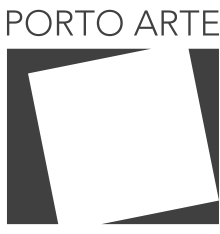

Revista de Artes Visuais

.25 ก. 44 $\mathrm{Jul} / \mathrm{dez} 2020$ e-ISSN: 2179-8001

\title{
Amostras de integração artística: Transferência de Estilo em Imagens usando Redes Neurais
}

Artistic integration's Samples: Image Style Transfer using Neural Networks

\section{Carlos Henrique Gomes Correia}

ORCID: 0000-0001-9858-8065

Instituto Federal do Espírito Santo, Brasil

\section{Karin Satie Komati}

ORCID: 0000-0001-5677-4724

Instituto Federal do Espírito Santo, Brasil

\section{Francisco de Assis Boldt}

ORCID: 0000-0001-6919-5377

Instituto Federal do Espírito Santo, Brasil

\section{Resumo}

Este trabalho faz um ensaio de combinação de duas imagens, denominadas de imagem-estilo e imagem-conteúdo, através de um sistema computacional que faz a transferência de estilo da imagem-estilo para a imagem-conteúdo, transportando a experiência visual, tais como paleta de cores, sombras e padrões de pinceladas da imagem-estilo e preservando as formas e objetos da imagem-conteúdo. Este sistema que integra arte e tecnologia utiliza Rede Neural Artificial, técnica inspirada no modelo biológico. Para as amostrasforam selecionadasfotos de locaisíconesnacionais como imagens-conteúdo, e obras de artistas brasileiros para serem as imagens-estilo.

Palavras-chave

Transferência de estilo. Redes Neurais. Integração da Arte e Tecnologia.

\section{Abstract}

This work makes an essay of combining two images, called image-style and image-content, through a computer system. Such a system transfers the style of the image-style to the image-content, transporting the visual experience, such as the color palette, shadows and brush strokes of the image-style and preserving the shapes and objects of the image-content. Such a system that integrates art and technology uses Artificial Neural Network, a technique inspired by the biological model. For the samples, photos of local national icons were selected as content images, and works by Brazilian artists to be the style images. 


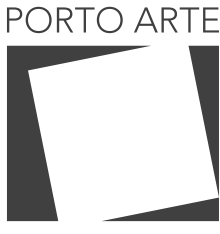

Revista de Artes Visuais

$\vee 25 n .44$

$\mathrm{Jul} / \mathrm{dez} 2020$ e-ISSN: 2179-8001

\section{Computação Bioinspirada}

Pesquisadores utilizam os comportamentos dos seres vivos como fonte de inspiração computacional para encontrar soluções para os problemas enfrentados pela humanidade. Para Marrow (2000), o desejo de que o comportamento dos seres vivos possa contribuir positivamente em pesquisas na área de computação inspiram profissionais que desenvolvem softwares e hardwares, originando o termo 『Computação Bioinspirada冈 (MEDEIROS et al., 2005). Evolução, ecologia, desenvolvimento, fenômenos celulares e moleculares, comportamento, cognição e sistemas neurais são objetos de estudo para esses pesquisadores.

Entre os seres vivos, os humanos possuem diversas habilidades consideradas excepcionalmente únicas, sejam elas cognitivas, motoras ou biológicas. Por isso, existem diversas pesquisas que têm como objetivo criar sistemas computacionais que simulam habilidades e características humanas a fim de encontrar soluções para os mais diversos problemas. Vários benefícios podem ser alcançados com a criação de sistemas com capacidade de simular habilidades humanas. Entre eles podemos citar: aumento de produtividade, diminuição de riscos, diminuição de erros, aumento de escalabilidade, diminuição de custos, dentre outros. Além das vantagens citadas, existe a possibilidade de se encontrar evidências que ajudem a explicar o funcionamento de habilidades humanas ainda não totalmente compreendidas (FARDIN JR, KOMATI, DE SOUZA, 2003).

Diferente do trabalho de Stelarc, que trabalha na incorporação da tecnologia computacional no corpo humano (OLIVEIRA, 2019), este trabalho usa a tecnologia de rede neural artificial, que é um algoritmo inspirado na biologia humana, tentando reproduzir como o cérebro humano funciona.

No trabalho de Gatys, Ecker e Bethge (2016a, 2016b) foi apresentado um sistema que simulava a capacidade humana de criar experiências visuais únicas através da composição de uma interação complexa entre conteúdo e estilo de uma imagem. Segundo o autor, além de um prover um algoritmo para a criação de imagens artísticas, seu trabalho oferece um avanço no entendimento de como elas são criadas e percebidas pelos humanos. Ainda segundo o artigo, sua principal descoberta foi que as representações de conteúdo e estilo de uma imagem são separáveis em uma rede neural artificial.

A ideia é criar uma nova imagem artística a partir de duas imagens de entrada: uma \imagem de conteúdo囚, de onde será baseado o conteúdo da nova imagem, e uma \imagem estilo囚, de onde será baseado o estilo da nova imagem. 0 termo usado pelos autores Gatys, Ecker e Bethge (2016b) foi "Image style transfer $\bigotimes$, ao qual traduzimos aqui como Transferência de Estilo em Imagens. A técnica de combinar o conteúdo e o estilo de duas imagens também foi usada por Smith (2016), e também pode ser utilizada em vídeos (RUDER et al., 2016) e jogos (YOO; KIM, 2016).

Para a experimentação foram escolhidas quatro imagens de conteúdo, fotos icônicas nacionais. Já para as imagens de estilo, optou-se por obras de artistas nacionais, afinal, o Brasil é celeiro de vários artistas com obras reconhecidas pelo mundo inteiro. 


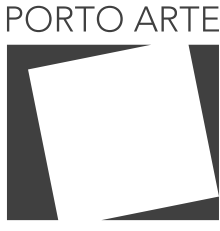

Revista de Artes Visuais

v $25 n \cdot 44$

$\mathrm{Jul} / \mathrm{dez} 2020$ e-ISSN: 2179-8001

\section{Arte e Tecnologia}

$\mathrm{Na}$ cultura digital, na qual vivemos, as manifestações e criações artísticas se utilizam cada vez mais das tecnologias digitais. Podemos encontrar diferentes interações entre a arte e a ciência na história. A relação entre música e tecnologia, por exemplo, influencia não apenas a linguagem musical como também acarreta a discussão sobre novas questões relativas à produção musical e ao mercado. É possível afirmar que a arte cinematográfica só foi possível pelo desenvolvimento de equipamentos tecnológicos, que influenciam diretamente a linguagem da grande tela. Nas artes plásticas a relação entre arte e ciência também é antiga. Pintores renascentistas aplicavam princípios da matemática para conferir ilusão de volume, textura e proporção harmoniosas no intuito de reproduzir as feições anatomicamente corretas (LOPES, 2015).

Algumas formas de arte possuem uma relação mais intrínseca com a tecnologia. A bioarte, por exemplo, é uma forma de arte contemporânea que adapta métodos científicos e biotecnologia para explorar sistemas vivos como objetos artísticos (YETISEN et al, 2015). Ela representa um cruzamento da arte com as ciências biológicas, utilizando a matéria viva como meio (STRACEY, 2009). A Neuroarte congrega uma série de expressões associadas a artes plásticas e neurociências. 0 termo expressa fenômenos mistos nas duas áreas, que podem ser fusões, influências de ambas as partes ou, inclusive, material artístico produzido por indivíduos que sofrem de problemas neurológicos ou psiquiátricos (ONDE..., 2004).

0 uso de sensores e atuadores que percebem o comportamento humano e respondem com estímulos auditivos e visuais inteligentes, os ambientes responsivos são uma forma de arte de interação homem-máquina, e que combina a utilização de computação gráfica, projeção de vídeo e outras tecnologias (MYRON, 1977). Instalações interativas são uma forma de arte onde as obras podem ser instaladas em espaços públicos. A criação dessas obras normalmente requer profissionais de diferentes áreas, como artistas, engenheiros, desenvolvedores de softwares e hardwares. Essas obras são criadas para reagirem às mudanças do espaço em que estão instaladas, tais como passagem do tempo, mudança de temperatura, luminosidade, nível da água. Também são desenhadas para reagir à presença e interação com espectadores (TRIFONOVA; JACCHERI, 2010).

A partir de 1990, surgiram vários estudos e técnicas com o objetivo de transformar imagens em obras de arte sintéticas de forma automática. A Arte Generativa é praticada por artistas que utilizam sistemas parcial ou completamente autônomos para contribuir ou produzir uma obra de arte completa (GALANTER, 2003). Também conhecida como de arte algorítmica, encontra interseção artística da programação, computação gráfica e expressão individual (PEARSON, 2011). Métodos clássicos apresentavam uma limitação em comum: utilizavam características de baixo nível das imagens e não capturavam suas estruturas corretamente.

O trabalho de Gatys, Ecker e Bethge (2016a, 2016b) criou um novo tema de pesquisa, o campo de Transferência de Estilo Neural, e atraiu a atenção da indústria e da academia (JING et al., 2019), pois supera a limitação citada. A produção de 


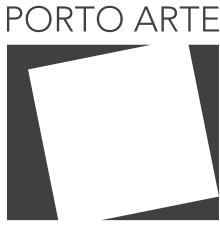

Revista de Artes Visuais

imagens apresentada neste artigo é um processo totalmente tecnológico. Ao mesmo tempo em que os resultados aqui apresentados mostram grande avanço em relação às técnicas anteriores, podendo causar uma sensação de estupefação e admiração, também podem causar uma sensação de aflição ou desconfiança. Para uma discussão mais ampla e profunda dessa contraposição entre tecnofobia e tecnofilia, indica-se o livro de Nunes (2010).

Para os desconfiados, citam-se as palavras de Domingues (2019):

São eliminadas barreiras das disciplinas para, num saber coletivo, realizar práticas colaborativas transdisciplinares, buscando níveis de realidade criativa em torno de objetos comuns de investigação.

Que neste mundo contemporâneo, é necessário se desfazer das amarras e olhar para a possibilidade de um futuro cada vez mais digital. Não é objetivo deste trabalho desenvolver uma discussão crítica sobre como o instrumental tecnológico se une à arte ou a arte se une à tecnologia. Para uma reflexão sobre a influência das tecnologias digitais nas práticas artísticas, aconselhamos a leitura do artigo de Bochio e Polidoro (2019).

O objetivo deste trabalho é apresentar uma técnica que pode ser apropriada por artistas no campo da arte para desenvolvimento de algoritmos a serviço de pesquisa poética, mas certamente não de gerar imagens que se pareçam com pinturas. Afinal, a arte faz uso das técnicas/tecnologias disponíveis no seu tempo.

\section{Aspectos Estilísticos x Aspectos Conteudistas}

O estilo nas artes visuais, resulta da abordagem usada para resolver questões pictóricas para expressar, da visão do artista, um determinado conteúdo. Nem sempre o estilo está desconectado do conteúdo. Os aspectos característicos do estilo são transversais à distinção entre forma e conteúdo, conforme Carney (2018), fazendo com que o estilo também inclui escolhas de assunto.

De forma diferente, neste trabalho, uma técnica de Inteligência Artificial (IA) é utilizada para criar representações distintas e manipuláveis do estilo e do conteúdo de uma imagem de entrada. Essas representações são estruturas de dados geradas pela técnica de IA e que depois podem ser utilizadas para gerar uma versão texturizada da imagem original, apresentando suas cores e estruturas localizadas, representando o estilo, e uma imagem apresentando os objetos da imagem de entrada, representando o conteúdo (Gatys; Ecker; Bethge, 2016a, 2016b). A divisão entre estilo e conteúdo é o resultado do processamento da rede neural artificial.

0 que a rede neural artificial considera como estilo são os elementos visuais que compõem a pintura, suas cores, a sensação de volume, o traçado das linhas, o fluxo das pinceladas que define o movimento dos objetos, a textura e as formas dos objetos. As linhas dividem planos e fecham contornos construindo formas e definem a nitidez 


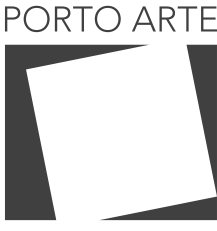

Revista de Artes Visuais v $25 n .44$ Jul/dez 2020 e-ISSN: 2179-8001

e precisão dos objetos da cena. 0 ritmo nas linhas expressa uma sensação de calma, movimento ou violência. A escolha das cores e a sua distribuição criam os efeitos de textura, sombras e volume. Faz parte do estilo essa composição de quais elementos existem, umas com mais intensidade que outras, bem como a organização no espaço destes elementos visuais. 0 estilo pode ser visto como uma fusão do estilo geral e do estilo individual. Considera-se que o estilo geral é dado pelas restrições estéticas de uma determinada escola, e o estilo individual é como o artista consegue se diferenciar usando as limitações dessa escola.

Já o conteúdo é o que a obra contém, quais são os objetos que a formam. Neste trabalho foram selecionadas fotos (e não obras) de locais, onde não há abstracionismo, apenas o concreto e objetivo, havendo poucos objetos em cena. Esta escolha não é por limitação da técnica, e sim, porque se considera de mais fácil visualização dos resultados da aplicação técnica. A seleção foi baseada em pontos turísticos comumente associados ao Brasil.

\section{Redes Neurais Artificiais para transferência de estilos artísticos}

Jones (2017) descreve um histórico da área de pesquisa de Inteligência Artificial (IA), mostrando que a busca dos seres humanos em desenvolver uma máquina inteligente começou nos anos 50 . Nos anos 80 surgia a área de aprendizado de máquina, que tem por objetivo desenvolver modelos que aprendem através de exemplos para a realização de tarefas de previsão e classificação dentro de domínios específicos. Ainda nessa área, em meados dos anos 2000, surgiu o deep learning (um tipo de rede neural artificial), algoritmo capaz de resolver problemas complexos em vários domínios. $\mathrm{Na}$ década passada, surgiu a computação cognitiva, focada na construção de sistemas que possam conhecer e interagir naturalmente com seres humanos.

Uma das abordagens de IA são as redes neurais artificiais, que foram inspiradas no modelo do cérebro humano. As redes possuem uma ou mais camadas compostas por nodos, nós ou neurônios, que são baseados em neurônios biológicos e servem como unidade simples de processamento. Existem diferentes arquiteturas de redes neurais, uma delas é a CNN (Convolutional Neural Network, em português Redes Neurais Convolucionais), que é rede neural artificial com várias camadas ocultas (LECUN et al., 1998). $O$ alto número de camadas confere uma poderosa habilidade de aprendizado e a capacidade de lidar com padrões e objetos complexos (tais como imagens) em grandes bases de dados (KIRANYAZ et al., 2019). Cada camada numa CNN pode ser entendida como uma coleção de filtros que, aplicados nas imagens de entrada extraem diversas características. Cada camada produz uma versão diferente da imagem de entrada.

De uma forma lúdica e simplificada, podemos pensar como se fosse um número decimal, tal como 9.234, e cada uma de quatro camadas da rede retornassem os dígitos 9, 2, 3 e 4, e em que a ordem de cada camada teria um peso, 1.000, 100, 10 e 1, respectivamente. É possível pegar o resultado de apenas uma camada e tentar recriar o número original. Se for o resultado da primeira camada, o valor 9 , o número recriado seria 9.000, que é próximo ao valor de entrada 9.234. Com o resultado da última camada, 


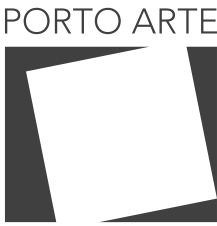

Revista de Artes Visuais

1.25 n. 44 $\mathrm{Jul} / \mathrm{dez} 2020$ e-ISSN: 2179-8001

o valor seria 4, que é mais distante do valor de entrada. Seria possível juntar o resultado destas duas camadas e gerar o valor 9004 .

De forma similar, uma imagem pode ser separada em partes, além disso é possível recriar uma imagem utilizando os dados de uma ou mais camadas da CNN. A imagem recriada com os dados das camadas iniciais reproduze imagens que são mais próximas do original, enquanto a imagem recriada com dados das próximas camadas apresenta informações cada vez mais abstratas da imagem original.

Aproveitando-se desta característica das CNNs, Gatys, Ecker e Bethge (2016a, 2016b) propuseram uma arquitetura de CNN que mistura duas imagens: uma imagem de conteúdo e uma imagem de estilo. A representação de estilo tem por objetivo capturar a informação de cor e textura de uma imagem, enquanto a imagem de conteúdo deve preservar a informação de forma. As primeiras camadas da representação de estilo contêm informações de maior granularidade e as últimas as de menor granularidade da textura, e as camadas de conteúdo armazenam principalmente a forma dos elementos, e a cada camada, diminui o nível de detalhes das formas.

O método de criação de imagem artística se baseia no método de geração de imagem a partir da representação de conteúdo de uma ou mais camadas da rede neural e da representação de estilo de uma ou mais camadas de outra rede neural. Assim, o método gera uma versão texturizada da imagem de entrada, enfatizando as cores e estruturas localizadas captadas pela representação de estilo.

\section{Galeria de Imagens de Conteúdo}

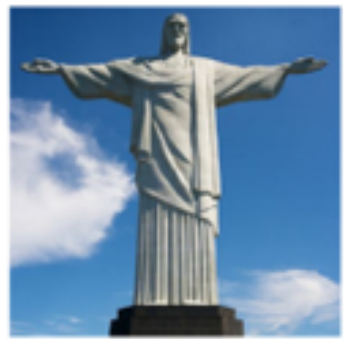

(a) Cristo Redentor

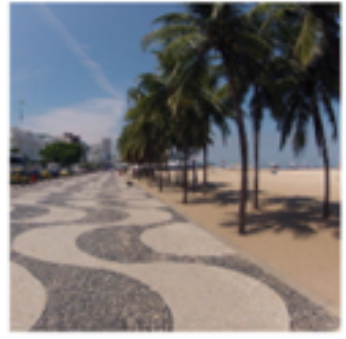

(c) Calcadio da praia de Copocabana

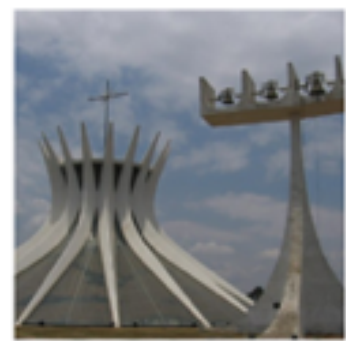

(b) Catedral de Brasilia

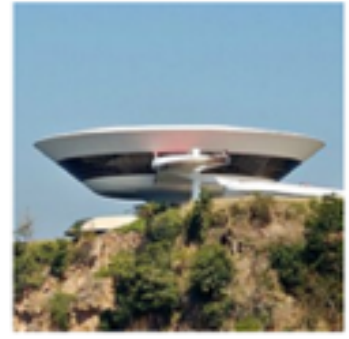

(d) Muscu de Arte Contemporânea de Niterói conteúdo (a) Cristo Redentor autor: Nico Kaiser, data: 23 de abril de 2011 (b) Catedra de Brasília, autor: Javier Gil data: 01 de setembro de 2006 c) Calçadão de Copacabana autor: Allan Fraga, data: 08 de Arte Contemporânea de Niterói, autor: Rosino, data licença CC-BY-SA-2.0 


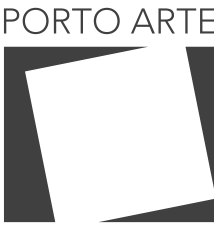

Revista de Artes Visuais

V. $25 n .44$ Jul/dez 2020 e-ISSN: 2179-8001

Figura 02 - Imagens de estilo (a) Abaporu, autor da reprodução fotográfica: Romulo Fialdini, data: 03 de marco de 2017 (b) Carnaval no

Morro, autor da reprodução

fotográfica: desconhecida

(c) Namorados, autor da reprodução fotográfica: Projeto Portinari, data: 23 de fevereiro de 2017 (d) A Ventania, autor da reprodução fotográfica: Romulo

Fialdini, data: 23 de fevereiro de 2017 (e) Cleópatra, autor da reprodução fotográfica: Romulo

Fialdini, data: 23 de fevereiro de 2017 (f) Baianas, autor da reprodução fotográfica: Sérgio

Guerini, data: 23 de fevereiro

de 2017 (g) Ladrão, autor da reprodução fotográfica: João L. Musa/Itaú Cultural, data: 23 de fevereiro de 2017 (h) Auto-

Retrato, autor da reprodução

fotográfica: Romulo Fialdini, data: 23 de fevereiro de 2017 (I) Bananal, autor da reprodução

fotográfica: Romulo Fialdini, data: 23 de fevereiro de 2017

Para a experimentação foram escolhidas quatro imagens de conteúdo, apresentadas na fig. 01, que são imagens icônicas nacionais: Cristo Redentor ${ }^{1}$, Catedral de Brasília $^{2}$, Calçadão de Copacabana ${ }^{3}$ e Museu de Arte Contemporânea de Niterói ${ }^{4}$. Todas sofreram um recorte de seu tamanho original para ficarem com 245 pixels de largura por 244 de altura.

\section{Galeria de Imagens de Estilo ${ }^{5}$}

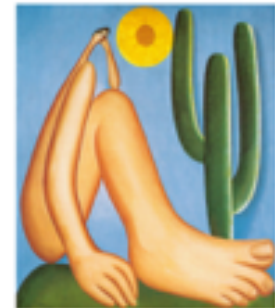

(a) Abaporu de Tarsila do Amaral

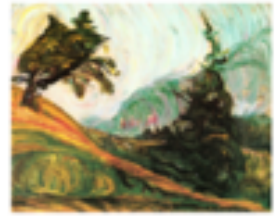

(d) A Ventania de Anita Mal. farti

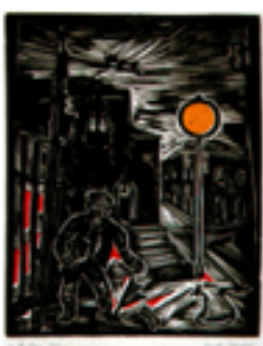

(g) O Ladtảo de Oswaldo Goeldi

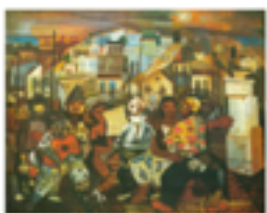

(b) Camanal no Morro de Di Cavalcanti

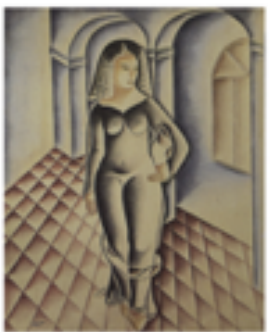

(e) Cloópatra de Vicente do Rego Monteiso

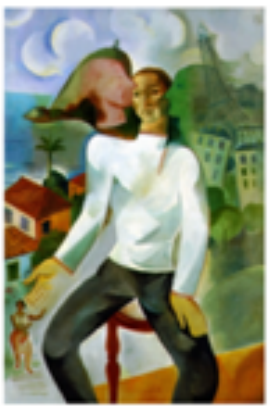

(h) Auso-Retrato de lsmael Nery

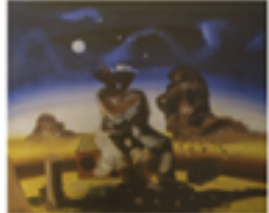

(c) Namorados de Candido Pertinari

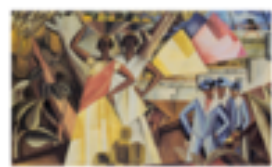

(f) Baianas de John Gra:

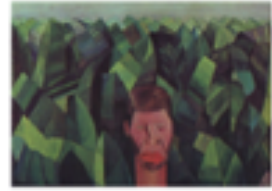

(i) Bananal de Lasar Segall
1-https://commons.wikimedia.org/wiki/File:Cristo_Redentor_-_Rio_de_Janeiro,_Brasil.jpg

2-https://commons.wikimedia.org/wiki/File:Catedral_de_Brasilia_en_Brasil.JPG

3-https://commons.wikimedia.org/wiki/File:Cal\%C3\%A7ad\%C3\%A3o_de_Copacabana_-_Rio_de_Janeiro_(2).JPG

4- https://commons.wikimedia.org/wiki/File:Niter\%C3\%B3i_Contemporary_Art_Museum_2011 a.jpg

5-De acordo com o parágrafo VIII, do artigo 46 da Lei 9.610 sobre direitos autorais, não constitui ofensa aos direitos autorais no caso de: VIII - a reprodução, em quaisquer obras, de pequenos trechos de obras preexistentes, de qualquer natureza, ou de obra integral, quando de artes plásticas, sempre que a reprodução em si não seja o objetivo principal da obra nova e que não prejudique a exploração normal da obra reproduzida nem cause um prejuizo injustificado aos legítimos interesses dos autores 


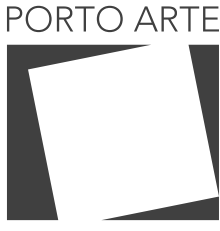

Revista de Artes Visuais

v $25 n .44$

Jul/dez 2020 e-ISSN: 2179-8001

Para esse trabalho, como imagens de estilo, foram selecionadas principalmente (mas não exclusivamente) imagens de obras de artistas brasileiros que ganharam notoriedade após a "Semana de Arte Moderna". Um dos grandes marcos na história de arte brasileira que ocorreu em São Paulo em fevereiro de 1922. A "Semana de Arte Moderna" é importante referencial para reflexões estéticas e para a crítica de arte do país (AJZENBERG, 2012).

A escolha das imagens modernistas se deve ao fato de terem um produto final com características mais destacadas para um apreciador leigo. A seleção é um contraponto, uma vez que a Arte e Tecnologia está inserida mais na arte contemporânea. Sendo assim, um diferencial nas amostras resultantes.

Os artistas e suas obras são apresentados na fig. 02. Os quadros são:

1- Abaporu (1928) de Tarsila do Amaral (ABAPORU, 2020), pintura a óleo, de tamanho $85 \times 72 \mathrm{~cm}$. Esta pintura a óleo inspirou o movimento antropofágico. A escolha das cores (verde e amarelo), formas e perspectiva da obra refletem a visão da artista de representar o Brasil. Apesar de ser um dos símbolos do modernismo brasileiro, Abaporu não esteve na Semana de Arte Moderna de 1922.

2- Carnaval no Morro (1963) de Di Cavalcanti (CARNAVAL , 2020). Óleo sobre tela, no tamanho $115 \times 146 \mathrm{~cm}$. Di Cavalcanti retrata a identidade e a realidade nacional, com temáticas ligadas ao cotidiano do povo do Rio de Janeiro. Utilização formas simplificadas e curvilíneas em cores quentes, em especial vários tons de vermelho.

3- Namorados (1940) de Cândido Portinari (NAMORADOS..., 2020), pintura a óleo, de tamanho $73 \times 60 \mathrm{~cm}$ sem moldura. A tela mostra uma composição nos tons vivos de azul e amarelo e nos tons terras, verde, preto, vermelho e branco. A textura predominante é lisa e espessa. Na saia do vestido branco há pinceladas espessas em branco. No chão, manchas de terra e verde com pinceladas mais claras que se prolongam para os lados dando efeito de sombras. Em segundo plano, uma faixa escura atravessa toda a largura da tela, um pouco acima do chão. Em terceiro plano, à esquerda e à direita, duas manchas de terras, a da esquerda é menor e mais clara que a da direita - que sugerem ser morros irregulares. Céu azul vivo em arco, com cores mais claras pouco acima da linha do horizonte, com lua cheia na metade superior esquerda.

4- A Ventania $(1915,1917)$ de Anita Malfatti (A VENTANIA , 2020), óleo sobre tela, de tamanho $51 \times 61 \mathrm{~cm}$. Na paisagem A Ventania, as formas foram construídas com cores que se movimentam na tela, confundindo os limites entre fundo e primeiro plano, englobando céu, terra e árvores. 0 vento é o elemento principal, ao movimentar os elementos da cena. Apresenta pinceladas de textura espessa, ressaltadas e rápidas, lembrando o trabalho do holandês Vincent van Gogh, assim, o vento se torna visível através de ondulações no céu.

5- Cleópatra (1950) de Vicente do Rego Monteiro (CLEÓPATRA, 2020), óleo sobre tela, de tamanho $190 \times 115 \mathrm{~cm}$. A tela apresenta influência cubista, mas bem diferente e único, com formas arredondadas no elemento central. Sendo que a textura do chão apresenta ladrilhos com sombras que dão a percepção 3D. 


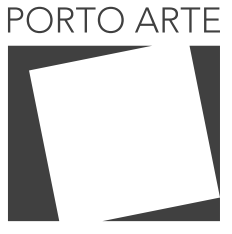

Revista de Artes Visuais

$\vee 25 n .44$

$\mathrm{Jul} / \mathrm{dez} 2020$ e-ISSN: 2179-8001

6- Baianas (1930) de John Graz (BAIANAS, 2020), óleo sobre tela, de tamanho $99 \times 169 \mathrm{~cm}$. Uma cena brasileira representada por traços geométricos. Elementos de primeiro plano em cores vibrantes com o segundo plano com cores mais escuras e menos distinguíveis.

7- O Ladrão (1955) de Oswaldo Goeldi (O LADRÃO , 2020), xilogravura, de tamanho $17,1 \times 21,6 \mathrm{~cm}$. Foi feito para o conto $O$ Ladrão, de Mário de Andrade, que conta a história de como um jovem que convence os moradores de uma vila a capturar um ladrão. A cena se passa à noite, e o preto e branco predomina, a forma do homem e os prédios são diluídos, de tal forma a não chamar a atenção inicial ao homem, dando a impressão de gatuno. As cores vermelho (chão) e amarelo (lâmpada), ambas cores quentes, destacam-se em meio ao fundo preto e branco, para onde o olhar é guiado.

8- Auto-Retrato (1930) de Ismael Nery (AUTO-RETRATO, 2020), óleo sobre tela, de tamanho $129 \times 84 \mathrm{~cm}$. No lado esquerdo é retratado o Rio de Janeiro de forma colorida, do outro lado, à direita, é retratado Paris, de forma monocromática. 0 elemento central, o próprio artista é retratado com traços cubistas com roupas em branco e preto. Demonstrando a neutralidade entre duas vidas, entre o Pão de Açúcar e a Torre Eiffel, entre o antigo e o moderno.

9- Bananal (1927) de Lasar Segall (BANANAL , 2020), óleo sobre tela, de tamanho $87 \times 127 \mathrm{~cm}$. Em primeiro plano tem-se a figura centralizada de um homem negro com traços cubistas e no fundo há uma densa plantação de bananeiras, que ocupam quase toda a superfície da tela, emparedando a figura central. O bananal é mais abstrato, com formas geométricas e diferentes tons de verdes e azuis. As linhas de contorno são sutis entre figura e fundo, mas as cores são bem contrastantes.

\section{Amostras de Integração de Estilo e Conteúdo}

Para alcançar o objetivo proposto, foi utilizado o código fornecido por Ganegedara (2019). 0 código faz uso das camadas do VGG16, um modelo de uma CNN treinada para reconhecimento de imagens, proposta por Simonyan e Zisserman (2014). No experimento, para criação das representações de conteúdo e estilo das imagens, foram utilizadas somente as sete primeiras camadas da VGG16. As imagens criadas a partir das imagens de conteúdo e de estilo são apresentadas na fig. 03 e na fig. 04. Foram criadas um total de 36 novas imagens que são combinações das imagens de conteúdo (na primeira linha) com as imagens de estilo (na primeira coluna).

$\mathrm{Na}$ segunda linha da fig. 03 são apresentadas as imagens geradas a partir do quadro Abaporu (1928). As novas imagens receberam as cores predominantes do quadro, mas elas estão aplicadas de forma diferente. No quadro, as cores estão presentes em regiões bem definidas, não há invasão de uma cor no espaço das outras. As cores presentes nas imagens geradas parecem se misturar e sobrepor umas às outras. Outra diferença muito evidente são as formas apresentadas nas imagens geradas que, ao contrário do quadro de Tarsila do Amaral, não possuem contornos bem definidos. Como resultado, as estruturas presentes nas imagens de conteúdos foram transformadas em estruturas com limites irregulares e, às vezes, de difícil identificação, como nos casos das imagens geradas a partir da fig. 01-c e fig. 01-d. 


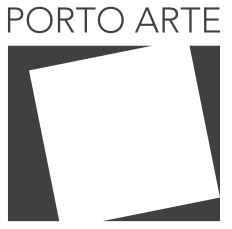

Revista de Artes Visuais

Jul/dez 2020 e-ISSN: 2179-8001
Figura 03 - Primeira amostra da transferência de estilo, a primeira linha são as imagens de conteúdo e a primeira coluna são as imagens de estilo, as imagens centrais são as imagens geradas pela integração de conteúdo

e estilo. As imagens geradas são do mesmo tamanho da imagem conteúdo, mas foram redimensionadas devido ao espaço do artigo. Fonte: autoria própria
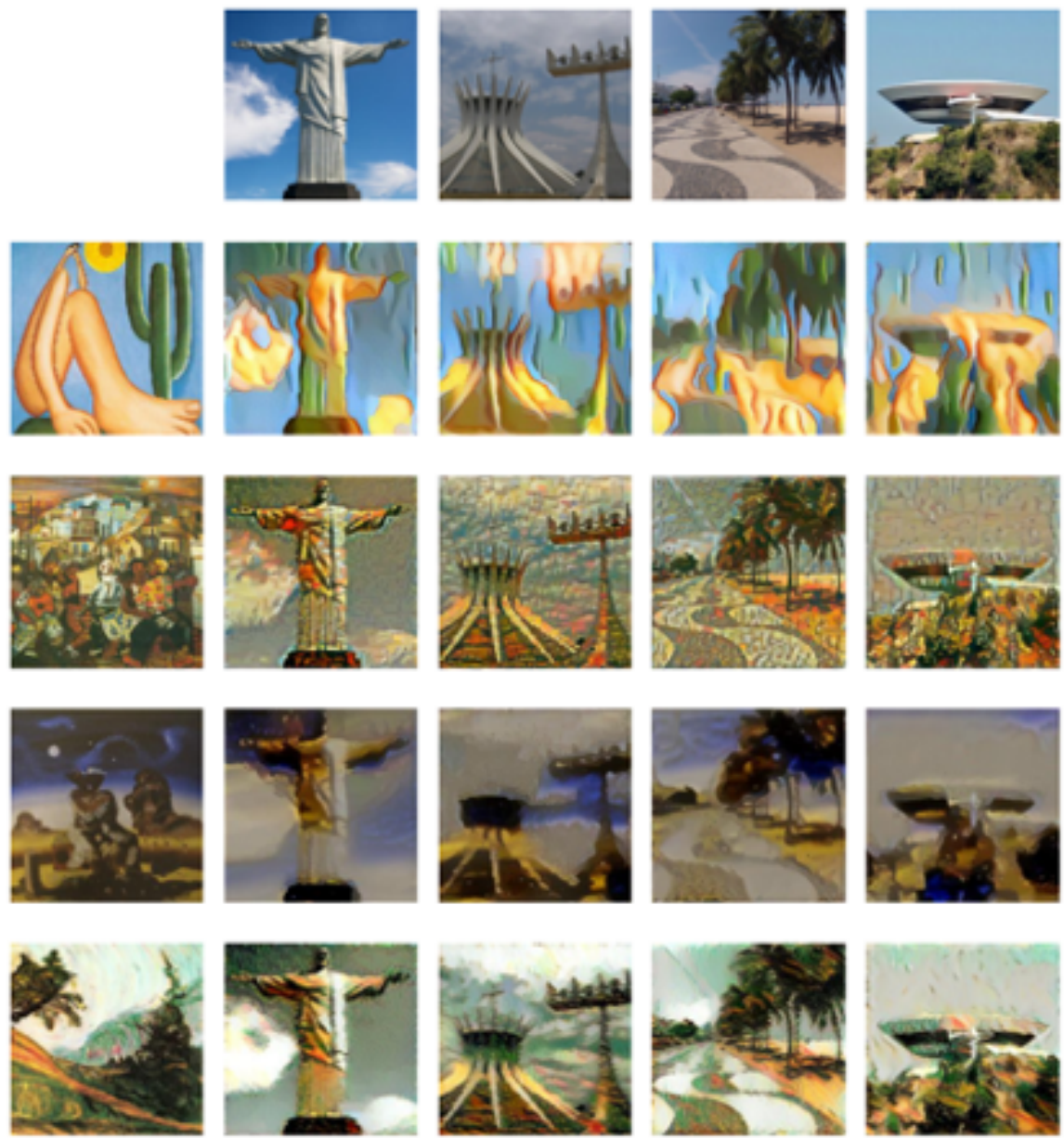

$\mathrm{Na}$ terceira linha da fig. 03 estão as imagens geradas a partir do quadro Carnaval do Morro (1963). As estruturas que aparecem nas imagens de conteúdo mantiveram suas linhas praticamente intactas, ou seja, não houve transferência dos estilos das formas mais evidentes do quadro, os personagens dançando, e nem desconstrução das formas proeminentes das imagens de conteúdo. As cores do quadro estão presentes nas novas imagens, porém os padrões formados por elas, no geral, não são semelhantes. Apesar disso, a impressão de textura formada imagens se aproximam daquela utilizada na parte superior do quadro, onde se encontra o céu pintado pelo artista. Um ponto a se notar é que perspectiva da imagem de conteúdo fig. 01-c é semelhante a do quadro, mas essa semelhança não contribuiu para que a imagem gerada a partir dela fosse mais parecida com o quadro do que as outras imagens. Neste exemplo, é possível considerar que não houve sucesso em transferir o estilo do quadro para as imagens, no sentido de que a mesma pessoa tenha pintado as novas imagens com os mesmos princípios artísticos, mas é possível constatar que as imagens geradas deixam a nítida impressão de que são quadros pintados com outro estilo. 


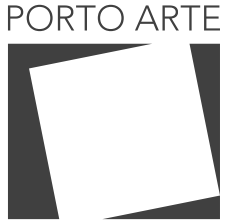

Revista de Artes Visuais

v. 25 n.44 Jul/dez 2020 e-ISSN: 2179-8001

Figura 04 - Segunda amostra da transferência de estilo, a primeira linha são as imagens de conteúdo e a primeira coluna são as imagens de estilo, as imagens centrais são as imagens geradas

pela integração de conteúdo

e estilo. As imagens geradas são do mesmo tamanho da imagem conteúdo, mas foram redimensionadas devido ao espaço do artigo. Fonte: autoria própria.
Na quarta linha da fig. 03 estão as imagens geradas a partir do quadro Namorados (1940). Em relação aos objetos presentes nas imagens de conteúdo, com a desconstrução de suas linhas de contorno e definição de detalhes, eles adquiriram um estilo visual muito mais semelhante ao do quadro. As cores também foram transferi-
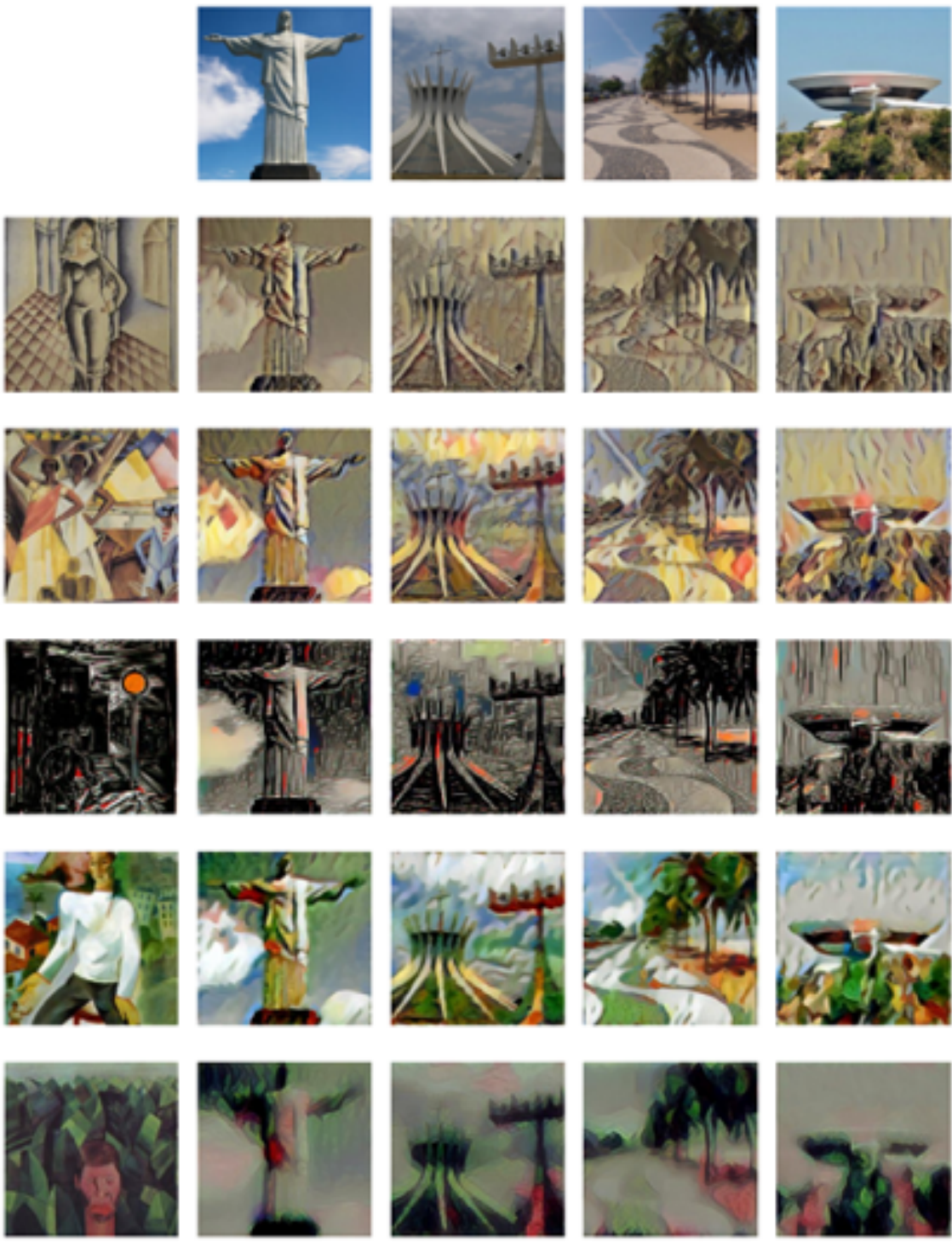

das para as novas imagens, mas em proporções diferentes. Enquanto os tons de azul e marrom predominam no quadro, tons de branco ficam mais evidentes nas imagens geradas. $\mathrm{E}$ a impressão de textura das imagens geradas está próxima ao da imagem de estilo. Apesar da composição de objetos da imagem de estilo ser diferente da com- 


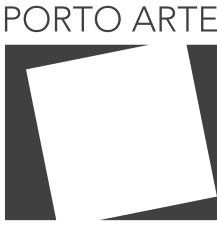

Revista de Artes Visuais

v $25 n .44$

Jul/dez 2020 e-ISSN: 2179-8001

posição das imagens de conteúdo, sendo muito mais complexa, as imagens geradas deixam a impressão de que poderiam ser criação do mesmo artista do quadro.

$\mathrm{Na}$ quinta linha da fig. 03 estão as imagens geradas a partir do quadro A Ventania $(1915,1917)$. Pode-se perceber que as cores da imagem de conteúdo foram aplicadas nas novas imagens. Algumas partes dos objetos das imagens de conteúdo, como a torre da fig. 01-b, os coqueiros da fig. 01-c e as pequenas árvores da fig. 01-d, sofreram transformações que as aproximam dos objetos da imagem de estilo. 0 restante dos objetos apresentou as cores e a impressão de textura do quadro. Em um aspecto geral, pode-se considerar que o estilo do quadro foi transferido para as novas imagens.

$\mathrm{Na}$ segunda linha da fig. 04 estão as imagens geradas a partir do quadro Cleópatra (1950). As cores da imagem de estilo estão presentes nas novas imagens em proporções semelhantes. É possível até identificar sombreamentos que são característicos da pintura. Algumas linhas apareceram nas imagens geradas, mas não trazem as mesmas características daquelas presentes no quadro, e a impressão de textura das novas imagens também são diferentes a do quadro. Neste exemplo, apesar das cores e das sombras presentes nas imagens geradas, não é possível dizer que o estilo do quadro foi aplicado com sucesso.

$\mathrm{Na}$ terceira linha da fig. 04 estão as imagens geradas a partir do quadro Baianas (1930). As imagens geradas apresentaram estruturas que remetem às estruturas geométricas da imagem de estilo, mas as composições que elas formam são diferentes. As cores do quadro também estão nas novas imagens, em proporções semelhantes em algumas imagens e proporções diferentes em outras. Apesar das cores presentes nas imagens geradas e de alguns elementos que lembram os traços geométricos do quadro, não é possível afirmar que seu estilo tenho sido transferido com sucesso.

$\mathrm{Na}$ quarta linha da fig. 04 estão as imagens geradas a partir do quadro $\mathrm{O}$ Ladrão (1955). As imagens geradas receberam as cores da imagem de estilo, mas em proporções bem diferentes. É possível perceber linhas nas imagens que remetem às linhas que definem os elementos da pintura, mas elas não têm a mesma função e parecem estar lá por acaso. Neste exemplo, o estilo do quadro não foi aplicado com sucesso nas novas imagens.

$\mathrm{Na}$ quinta linha da fig. 04 estão as imagens geradas a partir do quadro Auto-Retrato (1930). Apesar das novas imagens apresentarem as cores da imagem de estilo e a impressão de textura criada por pinceladas, elas não parecem ter o mesmo estilo do quadro. As cores se apresentam livres e sobrepostas enquanto no quadro elas são usadas em regiões bem definidas. As estruturas da imagem de estilo não aparecem nas imagens geradas, que terminam não mostrando traços que remetem às características cubistas. Apesar das cores e do aspecto de quadro, o estilo das imagens geradas difere, em muito, do estilo do quadro.

$\mathrm{Na}$ sexta linha da fig. 04 estão as imagens geradas a partir do quadro Bananal (1927). As cores do quadro foram aplicadas nas imagens geradas, mas em proporções bem diferentes. Enquanto no quadro há predominância de tons de verde, as novas imagens possuem mais áreas com tons de branco acinzentado. As linhas que definem os objetos das imagens também apresentam muita diferença. No quadro, é possível ver 


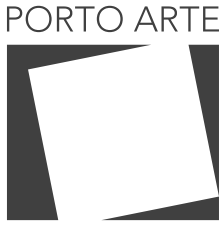

Revista de Artes Visuais v. 25 n. 44 Jul/dez 2020 e-ISSN: 2179-8001

com clareza as formas geométricas que criam o homem e as folhas de bananeiras, já os objetos das imagens geradas perderam definição, tal como se estivessem embaçadas e em nada remetem os traços cubistas. Não é possível dizer que o estilo do quadro foi aplicado com sucesso às novas imagens.

Os efeitos visuais de profundidade, tais como perspectiva (dado por ponto de fuga ou profundidade dada pela linha), superposição (quando um elemento sobrepõe outro), diminuição (formas que diminuem na pintura) e claro/escuro (luz e sombra), não foram notados na transferência de estilo.

\section{Considerações Finais}

Em um mundo cada vez mais digital e com inovações tecnológicas em diversas áreas, artistas exploram cada vez mais novas tecnologias, incluindo Inteligência Artificial, que está revolucionando as condições que obras de arte são produzidas, apresentadas, disseminadas, conservadas e recebidas (SIMMONS, 2019). A utilização de inovações tecnológicas no processo de criação nas diversas formas de arte sempre foi fonte de debate. Questiona-se se a intenção do processo é substituir o artista, se o produto final pode ser considerado arte ou se ele não é profano. 0 certo é que mudanças sempre são seguidas de resistências, e isso não é diferente com o uso de novas tecnologias na arte. Resistências que podem ser superadas com o passar do tempo e gerar avanços e novas oportunidades. Como outras inovações tecnológicas, as técnicas de IA, como a utilizada neste trabalho, têm mostrado que podem ser um campo fértil para novas formas expressão e criação artística, sem prejuízo para as já existentes.

Este trabalho apresenta uma pesquisa prática, descrevendo o processo de uso de Redes Neurais Artificiais como possibilidade tecnológica. 0 resultado observado é um olhar puramente estético do produto final, que pode ser considerado como um pastiche. Não foi realizado uma reflexão poética, na qual o caminho da produção, tais como as anotações visuais e esboços, narram o percurso poético para se chegar ao produto final e de como as técnicas não são neutras e implicam em significados que se somam ao tema e tantas outras camadas de significação.

A transferência de estilo usando Redes Neurais Convolucionais, técnica proposta inicialmente em 2016, traz novas alternativas estéticas. A técnica utilizada conseguiu gerar imagens que imitam o estilo de obras criadas por artistas, mostrando uma intertextualidade explícita. Foi possível reproduzir cores, criar efeitos de pintura e textura de pinceladas. Mas não é possível dizer que os estilos individual e geral apresentados nos quadros foram fielmente transferidos. As obras de artes mostram traços e características que traduzem a intenção do que o artista quer comunicar com sua obra. São esses traços e características que parecem faltar às imagens criadas pelo algoritmo. Entretanto, vale ressaltar os resultados das imagens geradas a partir da fig. 01-d, que apresentaram características muito próximas às do quadro, possivelmente, devido à simplicidade das composições de seus objetos e a forma como eles são definidos.

Uma possibilidade de melhorar os resultados seria alterar as configurações iniciais do algoritmo utilizado para gerar as imagens. No experimento, as mesmas 


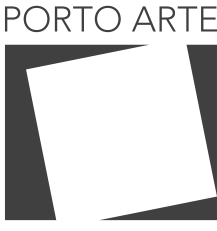

Revista de Artes Visuais

v $25 n \cdot 44$

$\mathrm{Jul} / \mathrm{dez} 2020$ e-ISSN: 2179-8001

configurações foram utilizadas com todos os quadros, mesmo assim os resultados gerados a partir de cada um deles foram bem diferentes. Logo, utilizar configurações específicas para cada quadro pode ser uma solução para se ter resultados que apresentem uma melhora na transferência de estilo. Explorar a utilização de várias possibilidades dessas configurações com obras de estilos diferentes pode ser objeto para novo trabalho. Um outro trabalho futuro seria o uso de múltiplos estilos para serem unidos em uma única obra.

O uso de CNN neste trabalho foi uma discussão sobre a natureza das imagens técnicas e de síntese, seu caráter de simulação e apresentação. No entanto, o uso de CNN em mistura de imagens pode ser muito polêmica, pois uma variação da CNN, a arquitetura GAN (rede contraditória generativa) pode ser usada para a geração de deepfakes (WAKKA, 2020) (DA SILVA, 2019a). A técnica permite a inserção do rosto de pessoas em qualquer tipo de vídeo de uma forma acessível em questões de segundos, reconhece padrões como movimentos, trações do rosto, voz e outras questões comportamentais fazendo com que o resultado seja muito próximo da realidade. Esse uso da IA com o propósito de manipular informações e opiniões, em geral de uso político, é crítico, pois chega a ser uma ameaça à democracia (DA SILVA, 2019b). É urgente e necessário se pensar em novos sistemas para diferenciar o que é um vídeo real e o que é um vídeo manipulado pela IA.

Ao mesmo tempo em que a técnica de Redes Neurais Artificiais pode gerar novas ferramentas, tal como a criação de filtros de softwares de edição de imagens baseados em estilos de pintores, que podem ser aplicados por artistas ou computadores, as deepfakes fazem com que se desconfie de seus próprios olhos. Essa perda de credibilidade 『no que seus próprios vêem $\bowtie$ pode mudar a relação humano-máquina, e é importante que se reflita sobre quais serão os seus impactos.

\section{Referências}

A Ventania. In: ENCICLOPÉDIA Itaú Cultural de Arte e Cultura Brasileiras. São Paulo: Itaú Cultural, 2020. Disponível em: <http://enciclopedia.itaucultural.org.br/ obra2047/a-ventania>. Acesso em: 02 de Jan. 2020. Verbete da Enciclopédia. ISBN: 978-85-7979-060-7.

AJZENBERG, E. A semana de arte moderna de 1922. Revista de Cultura e Extensão USP, 7, pp.25-29, 2012.

ABAPORU. In: ENCICLOPÉDIA Itaú Cultural de Arte e Cultura Brasileiras. São Paulo: Itaú Cultural, 2020. Disponível em: <http://enciclopedia.itaucultural.org.br/obra1628/ abaporu>. Acesso em: 02 de Jan. 2020. Verbete da Enciclopédia. ISBN: 978-857979-060-7.

AUTO-RETRATO . In: ENCICLOPÉDIA Itaú Cultural de Arte e Cultura Brasileiras. São Paulo: Itaú Cultural, 2020. Disponível em: <http://enciclopedia.itaucultural.org.br/ obra1320/auto-retrato>. Acesso em: 26 de Jan. 2020. Verbete da Enciclopédia. ISBN: 978-85-7979-060-7.

BAIANAS. In: ENCICLOPÉDIA Itaú Cultural de Arte e Cultura Brasileiras. São Paulo: Itaú 


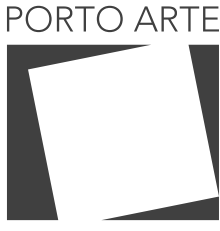

Revista de Artes Visuais v.25 n 44 Jul/dez 2020 e-ISSN: 2179-8001
Cultural, 2020. Disponível em: <http://enciclopedia.itaucultural.org.br/obra4748/ baianas>. Acesso em: 26 de Jan. 2020. Verbete da Enciclopédia. ISBN: 978-857979-060-7.

BANANAL. In: ENCICLOPÉDIA Itaú Cultural de Arte e Cultura Brasileiras. São Paulo: Itaú Cultural, 2020. Disponível em: <http://enciclopedia.itaucultural.org.br/obra1506/ bananal>. Acesso em: 26 de Jan. 2020. Verbete da Enciclopédia. ISBN: 978-857979-060-7.

BOCHIO, Alessandra Lucia; POLIDORO, Marina Bortoluz. Processos híbridos e a influência das tecnologias digitais nas práticas artísticas. Porto Arte: Revista de Artes Visuais. Porto Alegre: PPGAV-UFRGS, jan-jun, 2019; V24; N.40 e-88069 e-ISSN 2179-8001. DOI: https://doi.org/10.22456/2179-8001.88069.

CARNAVAL no Morro. In: ENCICLOPÉDIA Itaú Cultural de Arte e Cultura Brasileiras. São Paulo: Itaú Cultural, 2020. Disponível em: <http://enciclopedia.itaucultural.org.br/ obra4608/carnaval-no-morro>. Acesso em: 02 de Jan. 2020. Verbete da Enciclopédia. ISBN: 978-85-7979-060-7.

CARNEY, James D. A teoria estilística da arte. Tradução de Vítor Guerreiro. 2018. Disponível em: <https://criticanarede.com/lds_esteticaxix.html>. Acesso em: 26 de Jan. 2020.

CLEÓPATRA. In: ENCICLOPÉDIA Itaú Cultural de Arte e Cultura Brasileiras. São Paulo: Itaú Cultural, 2020. Disponível em: <http://enciclopedia.itaucultural.org.br/ obra2494/cleopatra>. Acesso em: 26 de Jan. 2020. Verbete da Enciclopédia. ISBN: 978-85-7979-060-7.

DA SILVA, Rafael Rodrigues. Deepfakes no Brasil | Parte 1: o estado das fake news brasileiras em 2019. 2019a. Disponível em: <https://canaltech.com.br/inteligencia-artificial/o-que-e-deepfake-e-como-ela-funciona-162167/. Acesso em: 10 out. 2020.

DA SILVA, Rafael Rodrigues. Deepfakes no Brasil |Parte 2: a ameaça fantasma de nossa democracia. 2019b. Disponível em: <https://canaltech.com.br/inteligencia-artificial/o-que-e-deepfake-e-como-ela-funciona-162167/. Acesso em: 10 out. 2020.

DOMINGUES, Diana Maria Gallicchio. Re-encanto do concreto por sistemas enativos afetivos: a naturalização das tecnologias no ecossistema. Porto Arte: Revista de Artes Visuais. Porto Alegre: PPGAV-UFRGS, v.24 n.40 / 2019: e-95975 e-ISSN 2179-8001 DOI: https://doi.org/ 10.22456/2179-8001.95975.

FARDIN JR, Dijalma; KOMATI, Karin S.; DE SOUZA, Alberto F. Arquitetura do Sistema Visual Humano: Uma Abordagem Computacional. III Escola Regional de Informática RJ/ES. Porto Alegre-RS: Sociedade Brasileira de Computação, p. 95-126, 2003.

GALANTER P. What is generative art? Complexity theory as a context for art theory. In GA2003-6th Generative Art Conference 2003.

GANEGEDARA, M. T. Intuitive guide to neural style transfer. 2019. Disponível em: <https://towardsdatascience.com/light-on-math-machine-learning-intuitive-guide-to-neural-style-transfer-ef88e46697ee>. Acesso em: 02 dez. 2019.

GATYS, L.; ECKER, A.; BETHGE, M. A neural algorithm of artistic style. Journal of Vision, As- 


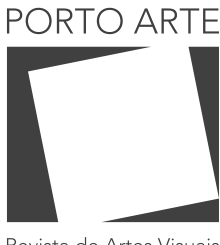

Revista de Artes Visuais $\vee 25 n .44$ $\mathrm{Jul} / \mathrm{dez} 2020$ e-ISSN: 2179-8001 sociation for Research in Vision and Ophthalmology (ARVO), v. 16, n. 12, p. 326, Set. 2016a. ISSN 1534-7362. Disponível em: <http://dx.doi.org/10.1167/16.12.326>

GATYS, L.; ECKER, A.; BETHGE, M. Image style transfer using convolutional neural networks. In Proceedings of the IEEE conference on computer vision and pattern recognition, pp. 2414-2423. 2016b.

JING, Y., YANG, Y., FENG, Z., YE, J., YU, Y. AND SONG, M., Neural Style Transfer: A Review, in IEEE Transactions on Visualization and Computer Graphics, vol. 26, no. 11, pp. 3365-3385, 1 Nov. 2020, doi: 10.1109/TVCG.2019.2921336.

JONES, M. T. Um guia para iniciantes sobre inteligência artificial, aprendizado de máquina e computação cognitiva. 2017. Disponível em: <https://www.ibm.com/ developerworks/br/library/guia-iniciantes-ia-maquina-computacao-cognitiva/ index.html>. Acesso em: 02 jan. 2019.

KIRANYAZ, S. et al.. 1D convolutional neural networks and applications: A survey. arXiv preprint arXiv:1905.03554, 2019. Disponível em: <https://arxiv.org/ pdf/1905.03554.pdf>.

LECUN, Y. et al. Gradient-based learning applied to document recognition. Proceedings of the IEEE, IEEE, v. 86, n. 11, p. 2278-2324, 1998.

LOPES T. Luz, arte, ciência... ação!. História, Ciências, Saúde-Manguinhos. 2005;12:401-18.

MARROW, P. Nature-inspired computing technology and applications. BT Technology Journal, Springer, v. 18, n. 4, p. 13-23, 2000.

MEDEIROS, TALLES \& MENEZES, ILG \& CARVALHO, MILENE \& GÓES, LUÍS. Computação Bioinspirada Aplicada à Robótica. In: IV Escola Regional de Informática de Minas Gerais - IV ERI MG, 2005, Belo Horizonte. IV IERI MG - Escola Regional de Informática de Minas Gerais. Belo Horizonte : PUC Minas, 2005. Capítulo 4.

MYRON W. KRUEGER. Responsive environments. In Proceedings of the June 1316, 1977, national computer conference (AFIPS '77). Association for Computing Machinery, New York, NY, USA, 1977, 423-433. DOI:https://doi. org/10.1145/1499402.1499476

NAMORADOS. In: ENCICLOPÉDIA Itaú Cultural de Arte e Cultura Brasileiras. São Paulo: Itaú Cultural, 2020. Disponível em: <http://enciclopedia.itaucultural.org.br/ obra1957/namorados>. Acesso em: 02 de Jan. 2020. Verbete da Enciclopédia. ISBN: 978-85-7979-060-7.

NUNES, Fabio Oliveira. Ctrl+ alt+ del: distúrbios em arte e tecnologia. FAPESP, 2010.

O Ladrão. In: ENCICLOPÉDIA Itaú Cultural de Arte e Cultura Brasileiras. São Paulo: Itaú Cultural, 2020. Disponível em: <http://enciclopedia.itaucultural.org.br/ obra32915/o-ladrao>. Acesso em: 26 de Jan. 2020. Verbete da Enciclopédia. ISBN: 978-85-7979-060-7.

OLIVEIRA, Andréia Machado. Aspectos biológicos e afetivos em arte e tecnologia. Porto Arte: Revista de Artes Visuais. Porto Alegre: PPGAV-UFRGS, jan-jun, 2019; V24; N.40 e-93550 e-ISSN 2179-8001. DOI: https://doi.org/10.22456/21798001.93550 


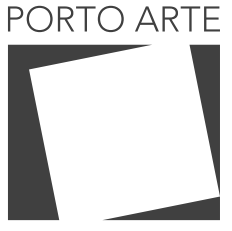

Revista de Artes Visuais

v. 25 n. 44 $\mathrm{Jul} / \mathrm{dez} 2020$ e-ISSN: 2179-8001

Onde a ciência se encontra com a arte. In: Cienc. Cult., São Paulo, v. 56, n. 1, p. 46, Jan. 2004 . Disponível from <http://cienciaecultura.bvs.br/scielo.php?script=sci_arttext\&pid=S0009-67252004000100030\&Ing=en\&nrm=iso >. Acesso em: 13 Out. 2020.

PEARSON M. Generative Art. Manning Publications Co.; 2011 Jul 7.

RUDER, M., DOSOVITSKIY, A., BROX, T. Artistic style transfer for videos. In German Conference on Pattern Recognition, pp. 26-36. Springer, Cham, 2016.

SIMONYAN, K., ZISSERMAN A. Very deep convolutional networks for large-scale image recognition. arXiv preprint arXiv:1409.1556. 2014. Disponível em: <https://arxiv. org/pdf/1409.1556.pdf\%20http://arxiv.org/abs/1409.1556.pdf>.

SIMMONS S. Drawing in the Digital Age: Observations and Implications for Education. InArts 2019 Mar (Vol. 8, No. 1, p. 33). Multidisciplinary Digital Publishing Institute.

SMITH, C. Y.. An Exploration of Style Transfer Using Deep Neural Networks. 2016. Disponível em: <https://digitalrepository.unm.edu/cs_etds/79>. Acesso em: 26 de Jan. 2020.

STRACEY F. Bio-art: the ethics behind the aesthetics. Nature Reviews Molecular Cell Biology. 2009 Jul;10(7):496-500.

WAKKA, Wagner. O que é Deepfake e como ela funciona? 2020. Disponível em: <https://canaltech.com.br/inteligencia-artificial/o-que-e-deepfake-e-como-ela-funciona-162167/. Acesso em: 10 out. 2020.

YETISEN AK, DAVIS J, COSKUN AF, CHURCH GM, YUN SH. Bioart. Trends in biotechnology. 2015 Dec 1;33(12):724-34.

YOO, B., KIM, K-J. Changing video game graphic styles using neural algorithms. In 2016 IEEE Conference on Computational Intelligence and Games (CIG), pp. 1-2. IEEE, 2016. 


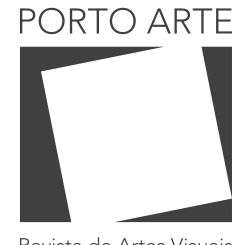

$\vee 25 n .44$ Jul/dez 2020 e-ISSN: 2179-8001

Texto submetido em: 07/03/2020 Texto aprovado em: 08/08/2020 Texto publicado em: 17/10/2020

\section{Carlos Henrique Gomes Correia}

Aluno de Mestrado em Computação Aplicada, com área de pesquisa em Inteligência Artificial. Bacharel em Ciência da Computação.

\section{Karin Satie Komati}

Doutora em Engenharia Elétrica, mestre em informática, bacharel em Ciência da Computação e Engenharia Elétrica, todos pela UFES. Atua em docência em nível superior desde 1998 e é professora do Ifes desde 2012. A área de pesquisa se concentra em Processamento Digital de Imagens, Reconhecimento de Padrões e Banco de Dados. Atual coordenadora do Mestrado Profissional em Computação Aplicada

\section{Francisco de Assis Boldt}

Doutorado em Ciência da Computação na área de Inteligência Artificial; Mestrado em Informática na área de Otimização de Redes Ópticas; Especialização em Desenvolvimento de Sistemas; Curso Superior de Tecnologia em Processamento de Dados.Professor do Ifes desde 2004.Áreas de pesquisa: Aprendizado de Máquina,Reconhecimento de Padrões, Redes Neurais,Processamento de Linguagem Natural,Processamento de Sinais, Detecção Automática de Defeitos em Processos Industriais. 